\title{
The Investigation of Undergraduate Course System Reform for the Major of Measure \& Control Technology and Instrument
}

\author{
Fangfang Han* \\ School of Electrical Engineering, \\ Tianjin University of Technology \\ Tianjin, China \\ fangfanghan2004@163.com \\ *Corresponding author \\ Hong $\mathrm{He}$ \\ School of Electrical Engineering, \\ Tianjin University of Technology \\ Tianjin, China \\ heho604300@126.com
}

\author{
Baofeng Zhang \\ School of Electrical Engineering, \\ Tianjin University of Technology \\ Tianjin, China \\ zhangbaofeng@263.net \\ Lina Liu \\ School of Electrical Engineering, \\ Tianjin University of Technology \\ Tianjin, China \\ linaliu_2006@163.com
}

\begin{abstract}
The major of Measure \& Control Technology and Instrument is the undergraduate program belongs to Instrumentation Science discipline, which researches the acquisition and processing of information, and the theory and technology for relevant elements control. It is involved in electronics, optics, precision machinery, computer, information and control technology and other high-tech multi-disciplinary technology. Since students' ability acquisition relying on the curriculum system, this paper discusses the professional courses training system design for the major of Measure \& Control Technology and Instrument combined with the technological development and social needs. For the purpose of education quality enhancing, and improving of students' ability, employability and competitiveness, it aims to develop high quality practices and innovation ability of talent.
\end{abstract}

Keywords- higher education; curriculum system; practical ability; instrument science

\section{INTRODUCTION}

University undertakes variety functions, but its most important task is the students' talent cultivation, while the task is realized by course teaching. The fundamental for innovative talents training is to construct the scientific and reasonable curriculum system, and this is achieved by teaching process ${ }^{[1,2]}$.

Curriculum is the process and arrangement of discipline contents that school students should learn, and it is the basic unit of teaching work of higher education. The curriculum system is an entirety system of the accumulation of practical knowledge by human and the courses through selection and organization from teaching ${ }^{[3,4]}$. It includes not only the overall courses designed based on the school curriculum training objectives, but also includes specialized courses contacted with each other, and also includes only one course structure system.
It is the main carrier to realize the goal of talents cultivating for higher education, and the bridge for education ideas and concepts to education practice, what's more, it is also the basis of major construction. Whether the curriculum construction is scientific and reasonable decides the level of student's knowledge, ability and quality structure after the process of teaching, and decides whether the school's training objectives can be achieved. Therefore, the curriculum system construction is the core issue of university education management, and it is directly related to the realization of the training objectives of higher education, and related to the higher education schools' running characteristics.

As the only undergraduate major in the field of measurement and instrument science, the major of Measure \& Control Technology and Instrument has become an important branch of the information science and technology disciplines, which researches the acquisition and processing of information, and the theory and technology for relevant elements control. The major is a high-tech intensive integrated discipline merged together with mechanics, optics, computer, automatic control technology and information technology ${ }^{[5-7]}$. And with the rapid development of modern science and technology, as the pillar of the knowledge economy, the industry of information technology will also be enhanced rapidly, and more and more variety of high-tech techniques will penetrate into the measurement field and instrumentation industries. The development of science and technology not only makes the need for specialty talented person with the major of Measure \& Control Technology and Instrument greatly increased in more and more areas of research and application, and with the acceleration of knowledge updating, the times of Knowledge-Economy is imminent to cultivate a large number of the talented persons with comprehensive quality, practical ability and innovation capability. Therefore, it 
makes the talent cultivation for the major of Measure \& Control Technology and Instrument to put forward some new requirements ${ }^{[8,9]}$.

\section{DEVELOPMENT OF THE MAJOR OF MEASURE \& CONTROL TECHNOLOGY AND INSTRUMENT IN OUR SCHOOL AND THE SHORTAGE OF THE EXISTING CURRICULUM}

According to the long-term development program of Tianjin Higher College, Tianjin University of Technology is a multi-subjects comprehensive university with the characteristics of electronic information disciplines, paying equal attention to scientific research and teaching, and mutual development in undergraduate education and postgraduate training. The major of Measure \& Control Technology and Instrument belongs to Electrical Engineering School of our university, and it is one of information major of this school. This major was founded in 1983, and after major adjustment in 1996, it broadened the professional caliber, and formed a hightech intensive integrated discipline merged together with mechanics, optics, computer, automatic control technology and information technology. The training objective of this major must highlight our school-running orientation of service the regional economic development and cultivating applied undergraduate talents. The training objective of this major in our school is: based on information science theory, cultivating senior engineering and technical personnel in the field of Control Technology and Instrument with high-level, highquality, innovative spirit, research ability and inter-disciplinary talent.

After years of development, undergraduate training scheme of the major of Measure \& Control Technology and Instrument has been revised many times. But the scheme now executed has the following main problems:

- Scientific technology is changing with each passing day, if do not any revise for the course scheme for a period of time, some contents of some courses will be "out of date", then there will be a large difference with students employment requirements.

- The contents of one course is usually some repetition of the contents of many other courses. This also reflects a problem of undergraduate training scheme: for the undergraduate course, especially for professional course, whether is "hodgepodge" of teaching a lot of content in one course to expand students' knowledge well, or for one theory to explain in one course deeply is better?

- Professional elective courses is executed with a low rate, and the core ability training for students is not clear. Although many professional elective courses are listed in the course scheme, but the students usually only concern with credits and only select some courses with higher credits, so a lot of good professional elective courses can not be executed. Therefore, seemingly completive course scheme has much weakness in students ability cultivating. So it is necessary to have a reasonable elective law for professional elective courses.
- There are some shortage in practical teaching links, for example, most experiments are mainly based on computer simulation, and the teachers always arranged everything well for students before experiments. Those phenomenon make our students lack of innovation knowledge and exploration spirit, and against the original purpose to improve students' hands-on ability, and to some extent, it restricts the effects of practical teaching links.

\section{SCHEME FOR COURSE SYSTEM REFORM}

\section{A. The General Idea}

According to the self-positioning of our university, the training goal for the major of Measure \& Control Technology and Instrument in our university should be: meeting the need of local economic construction and social development, researching the acquisition and processing of information, and the theory and technology for relevant elements control, and cultivating application-oriented professionals own the basic knowledge and the ability for instrumentation, measurement and control technology design and manufacture, and have the innovation spirit and practical ability for the works researching and management in all kinds of departments of national economy.

So the general idea for the course system reform of the major of Measure \& Control Technology and Instrument is:

- The curriculum system should be able to reflect the basic requirements for knowledge and ability training for mechanics, optics, computer, automatic control and information technology.

- The core ability for students cultivating should be proposed explicitly, and put forward the idea for core courses supporting the core ability cultivating.

- Specialized courses setting should try to reflect the features and advantages of this university and this major, and highlight the characteristics of students' ability.

\section{B. Teaching Courses setting}

Curriculum system has converted from traditional geometric measurement to informational orientation that includes optics, electricity and other mainstream technology, and then it put more emphasis on information acquisition, processing, and the theory and technology for relevant elements control. The purpose is to enable students to master the technical knowledge to adapt to the needs of today's society, enhance students' information processing ability and increase the rate of employment. So we set two professional orientations and provide some different optional courses for the two orientations. Then it will give students more choices according to their interests and also can increase the execution rate of professional elective courses. The reformed teaching courses setting are shown in Fig.1.

As shown in Fig.1, basic competence of discipline in mechanics, optics, electricity, calculate and control theory are mainly reflected by the academic foundation courses, then the courses such as Mechanics, Optics, Electricity, Precision 
Machinery, Microcomputer Principle, Sensors and Control theory are set. Professional elective courses are divided into two orientations of photoelectric detection and industrial instrument design. The common shared parts in elective courses are recommended to all students to choose, and the other two parts for two orientations are arbitrarily selected by students according to their interests.

According to the self-positioning of this major in our university, put forward the core abilities the students should master are: information acquisition, information processing, and measure-control instruments design. The ability of information acquisition is reflected by the courses of Sensors and Testing Technology, Photoelectric Detecting Technology, Measurement and Control Circuit, Laser Application Technology, etc. The ability of information processing is reflected by the courses of Signal and System, Digital Signal Processing, Image Processing and Computer Vision, Error Theory and Uncertainty Evaluation, etc. The ability of measure-control instruments design is reflected by the courses of Measurement and Control Circuit, Process Control System, Micro-controller Principle and Application, Embedded System Design, Measure-control Instrument Design, Field Bus and Control Network, and so on. Thus, we achieve the idea that students core ability cultivating should be supported by core courses.

Based on teachers' ability, scientific research direction and professional service direction, the main feature and advantage of this major in our university is in the direction of photoelectric detection. Therefore, the feature and advantage are reflected by the courses of Photoelectric Detecting Technology, Digital Signal Processing, Image Processing and Computer Vision, Laser Application Technology, and so on.

\section{The arrangement of Practical Teaching Links}

The practical teaching links of this major mainly includes the following aspects: course experiments, course design, professional comprehensive experiments, professional design, graduation design, productive practice and graduation practice. It can be seen that there are various practical links. Then how to arrange the specific content of those links to make every link not only have its own characteristics and training pertinence, but also can complementary with each other, is another important research topic. This paper proposes the practical teaching links arrangement scheme shown as Fig.2.

For the practical teaching links arrangement, we not only considers the content for only one link separately, but put forward the idea that "cascade" all links as a whole practical scheme to think about. As shown in Fig.2, through the "cascade" setting mode and the following contents arrangement measures to make students' practical ability achieve a progressive and comprehensive exercise and improvement: from practice aimed to one course to comprehensive practice merged with more courses; from one project task for all classmates, to one project task for three students and to one project task for only one student at last; from school laboratory to off-campus enterprise training mode.

\section{CONCLUSION}

The major of Measure \& Control Technology and Instrument is an important branch of Instrument Science. It provides important methods to objective things for detection, measurement, monitoring and control. Many tasks such as basic research and experimental work, national economic construction of modern defense, modern industry, modern agriculture and human social life, are inseparable from the instrumentation and measurement techniques. Therefore, it plays a very important role in the national economy.

The study for the training mode of the major of Measure \& Control Technology and Instrument in our school still needs continuously improvement in practice, so that we can promote education quality, keep up with the pace of modern society's development, and enhance application personnel training efforts.

For the reform of undergraduate course system of the major of Measure \& Control Technology and Instrument, in the longtime practice work in the future, it still needs to carry out the following aspects to achieve continuing development and improvement:

- Update the values of curriculum, and to realize the modernization of the curriculum system.

- Strengthen the reform of theoretical curriculum, and to achieve integration of the curriculum system.

- Strengthen the practical teaching links, and put emphasis on the training of students' practical ability.

- Have the courage for education innovation, and achieve the characteristic construction of the curriculum system.

\section{ACKNOWLEDGMENT}

This work is supported by the Teaching Reform Project of Tianjin University of Technology (YB12-61) and Tianjin Institution of Higher Learning Foundation for Development of Science and Technology (No. 20130706).

\section{REFERENCES}

[1] Liu Daoyu, "Theory of university curriculum system reform", Higher Education Exploration, 2009, 1: 5-9

[2] Sun Weiguo, "Explore for undergraduate course system based on personal development", Journal of National Academy of Education Administration, 2011, 7: 3-7

[3] Gao Xue, "Thinking about the theory of construction of undergraduate course system", Journal of Tibet Nationalities Institute (Philosophy and Social Sciences), 2012, 33(1): 118-121

[4] Guo Guiying, Chen Ling, "Innovation and optimization of engineering undergraduate curriculum", Journal of Yancheng Institute of Technology (Social Science Edition), 2006, 3: 77-80

[5] Pan Shenghui, Chen Zhengqiang, Cui Huiliu, "The exploration and practice of Measurement and Control Technology \& Instrument professional training model", Higher Education Forum, 2005, 10: 52-53

[6] Liu Lili, He Cunfu, Song Guorong, etc. "Exploration for A line system for practice teaching of the major of Measure \& Control Technology and Instrument", Experimental Technology and Management, 2005, 22(1): 93-95

[7] Wu Huazhi, Zhou Xiangcai, "Research and practice of applicationoriented talents cultivation on measure and control technology and 
instrument specialty", Journal of Changzhou Institute of Technology, 2004,8: 74-77

[8] Zhou Yan, Cao Yang, "On reforms of experiment teaching for detection and control courses", Journal of Jiangsu University(Hig her Education Study Edition), 2002,9: 80-82
[9] Song Aiguo, Kuang Yinghui, "Exploration for undergraduate talent cultivation system of Measure \& Control Technology and Instrument specialty", Research of higher education in engineering, 2005,1: 48-51

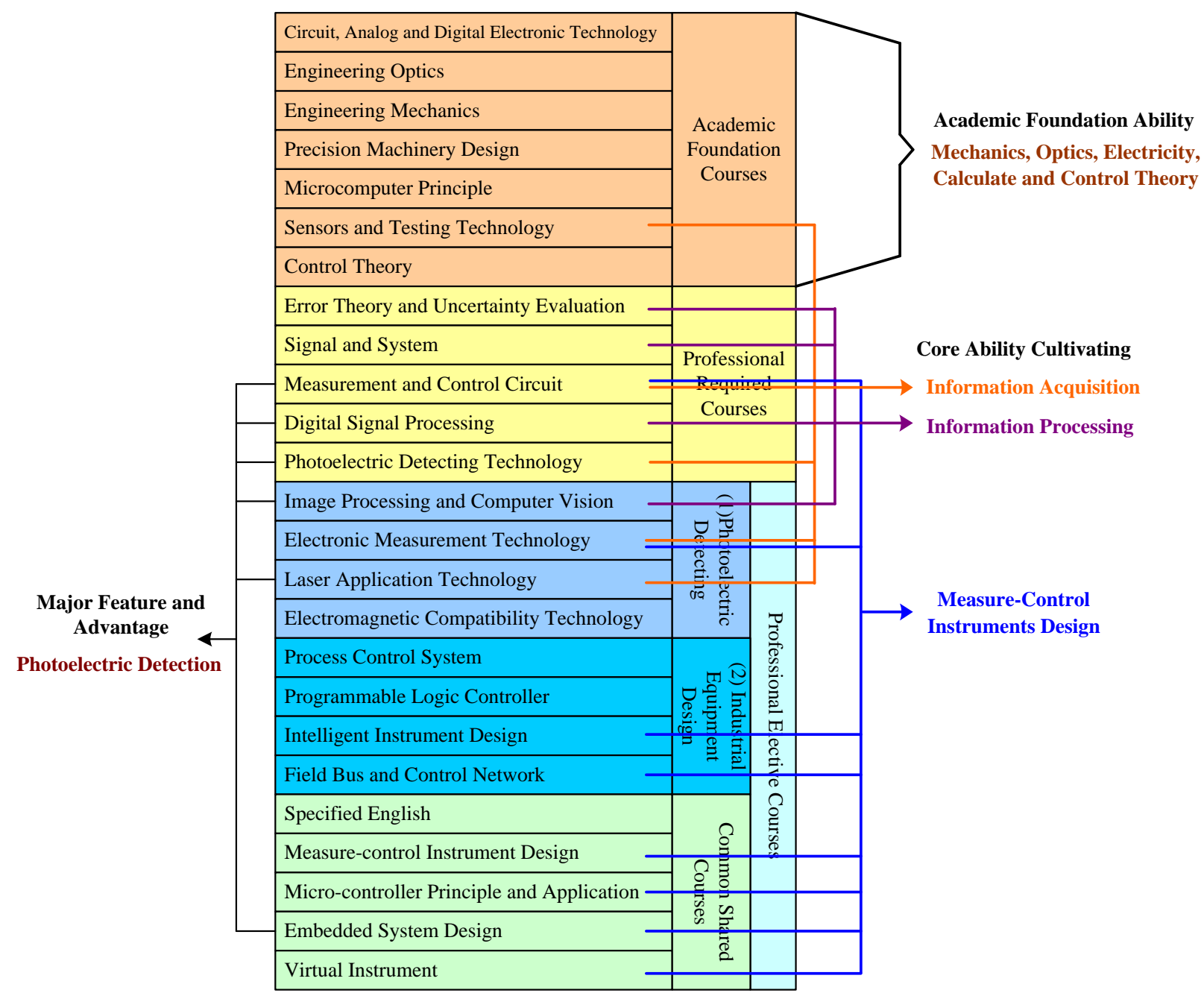

FIGURE I. REFORMED TEACHING COURSES SETTING

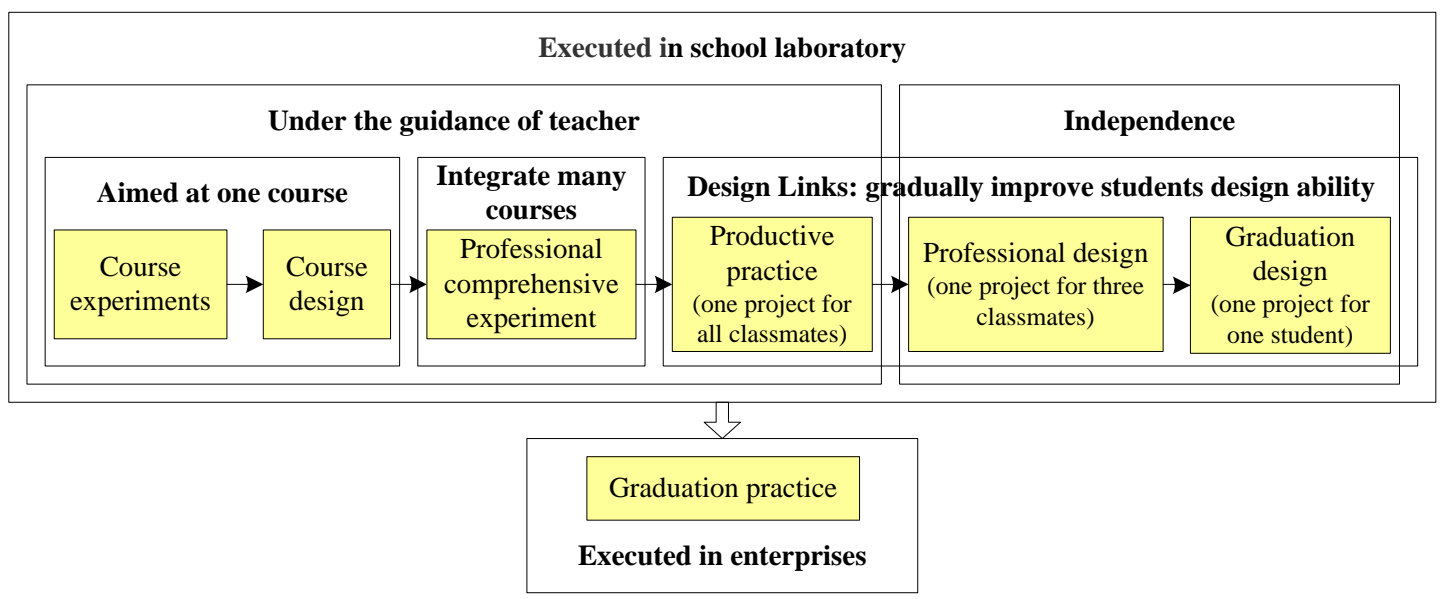

FIGURE II. PRACTICAL TEACHING LINKS ARRANGEMENT SCHEME 